\title{
What is happening to the natural landscape of Aotearoa?
}

\author{
Colin D. Meurk and Rowan P. Buxton \\ Botany Division, P.B., DSIR, \\ Christchurch
}

\begin{abstract}
Aotearoa is a restless land with an eventful though isolated history which has spawned many distinctive biological qualities. Human occupation decreased our isolation and increased rates of change. Consequently, our potential natural and cultural identity is in danger of being swamped by cosmopolitan, temperate elements. This has serious consequences for agriculture, tourism, our sensitivity to local and global environmental issues, and the development of a nationhood founded on sturdy roots that dig deeply into the texture and history of the land. We examine the values of natural landscape, concepts of land custodianship, a conservation ethic and practical ways of integrating protection of natural values and sustainable production.
\end{abstract}

Keywords change, conservation, culture, development, habitats, history, land management, landscape, vegetation

\section{INTRODUCTION}

To answer the title question we must understand: what our natural landscape is; how it differs from that of other temperate regions of the world; what have been the historical rates, magnitude and frequencies of change; what was left at the time of European contact; what is left now for future generations to inherit; how representative of the original heritage are our existing remnants and reserves; what does this mean to our grip on our history, culture, education, science, water and soil conservation ethic, tourism and landscape aesthetics?

\section{EVENTS THROUGH \\ GEOLOGICAL TIME}

New Zealand has a long and eventful history. We began as a chip off the old Gondwana supercontinent 80 million years ago, rafting to our present position, free of major intrusions or catastrophes until 10 million years ago when mountain building was in full swing, followed by glaciation and human settlement. Before this, life in New Zealand must have been a somewhat somnolent existence - free from mammalian browsers, grazers, predators, hunters and from 'herd' grazing birds. Soils were probably old, impoverished, leached or droughty and supported tropical or 'Savannah forms (largeleaved beeches, podocarps, coconut palms, eucalypts, proteas, casuarinas, and lowland precursors of the alpine flora). Things ticked over slowly with a premium on competitive stickability, in the closed vegetation of infertile, windy, oceanic environments, rather than on rapid responses to repeatedly defoliated or bared land.

Mountain building and climatic cooling caused a dramatic, adaptive radiation of life forms (already adapted to poor soils and oceanic exposure) able to occupy the alps. After the last glaciations the coldadapted species retreated upwards and southwards and the surviving warmth-lovers spread from the north.

Fires occurred from time to time, but there were no voracious mouths to follow up and devour the regrowth, hence delivering the coup de grace. Cataclysmic volcanism occurred, but still these were only regional and sporadic events.

\section{HUMAN HISTORY}

Fire freqency increased with the arrival of the first settlers from the Pacific about 1000 years ago. It was their hunting, and accompanying rats and dogs, that had the irreversible effect on the bird life and some invertebrates. The succeeding major wave of settlement came from Europe, complete with potentially destructive technologies and millions of grazing, draught and predatory mammals. and those European plants that had the defences and regenerative powers, missing from the indigenes. to prosper under a regime of continual perturbation.

\section{THE LONG CONTEXT OF CHANGE}

The impacts of long term stasis and cyclical change are generalised in Figure 1. The last 2 million years have been punctuated by tectonics. glaciation and volcanism, but even this pales beside the magnitude and comprehensiveness of change, and the limited time for adjustment, in the last 200 years. Forty-four species of birds have been lost and 15 are threatened. eight plant species are gone from the wild. but the habitats and genetic diversity of all are greatly contracted, and many more species are on the brink of extinction. The picture is probably similar for freshwater fish. amphibians and 
invertebrates (Holdaway 1989). Species can adapt or migrate during 2 million years or even deal with gradual changes over 20000 years? but 200 is just , not long enough. There is no escape! (Remember that during the glaciation plants could seek refuge by migrating down to shelter at coastal environments below present sea level.)
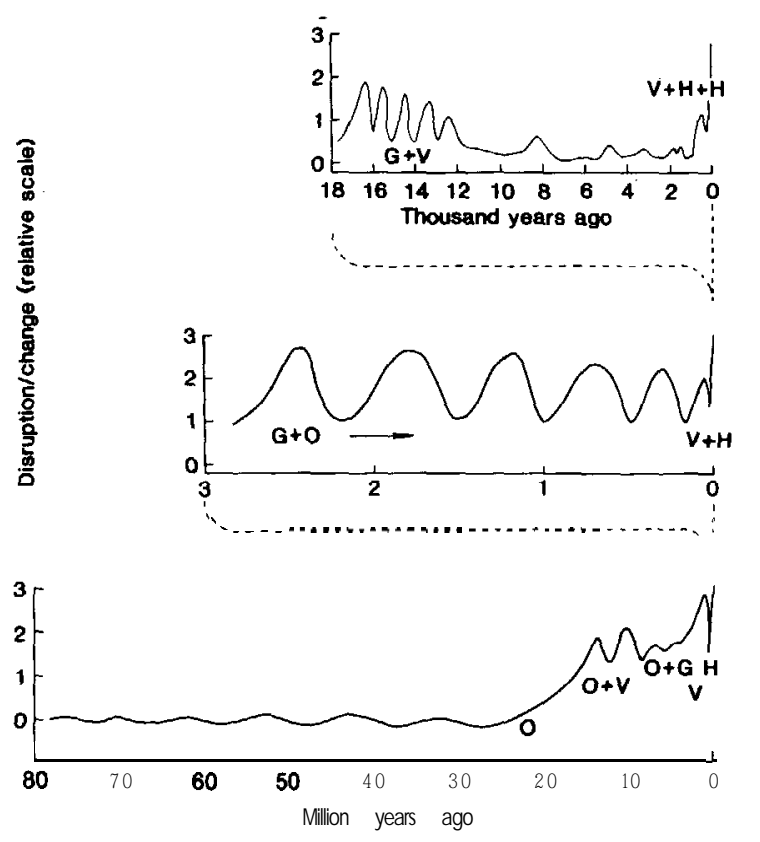

Figure 1 Perspective on change in New Zealand during three time frames as generated by orogeny $(\mathrm{O})$, volcanism (V), glaciation $(G)$ and human intervention $(\mathrm{H})$.

\section{LANDSCAPE PATTERNS FROM YESTERYEAR TO THE PRESENT DAY}

The broad, natural patterns that greeted the first settlers of Aotearoa can be deduced from the remaining fragments, as summarised in Figure 2. Where moisture is not severely limiting there is a latitudinal/altitudinal sequence of warm temperate tall, mixed forest, cool temperate beech or low, mixed forest, and alpine shrublands, grasslands, herbfields, rock and ice. Cutting across these thermal patterns are the effects of aridity (especially in the eastern plains, hills and basins) which reduce vegetation stature, density and to some extent diversity. At yet finer scales are. the imprint of topography, drainage, and rock and soil substrates. Finally, history overlays its indelible mark on the patterns and processes of nature - whether it's from the dim past (which species got here, how quickly they could colonise or recolonise) or the result of contemporary management (the suppression of wild growth in maintenance of pastures, crops, etc).

\section{MYTHS, LEGENDS AND TRUTHS}

Sadly, our history has been neglected. There are many misconceptions about our land and its origins (the totality of landscape). Despite common knowledge, New Zealand has virtually no deciduous trees in the native flora; deer, pigs and opossums are aliens here; all clovers and most coloured flowers are introduced; the open lowland forests are unnatural, their undergrowth having been stripped by less than a century of trespassing by stock and feral animals.

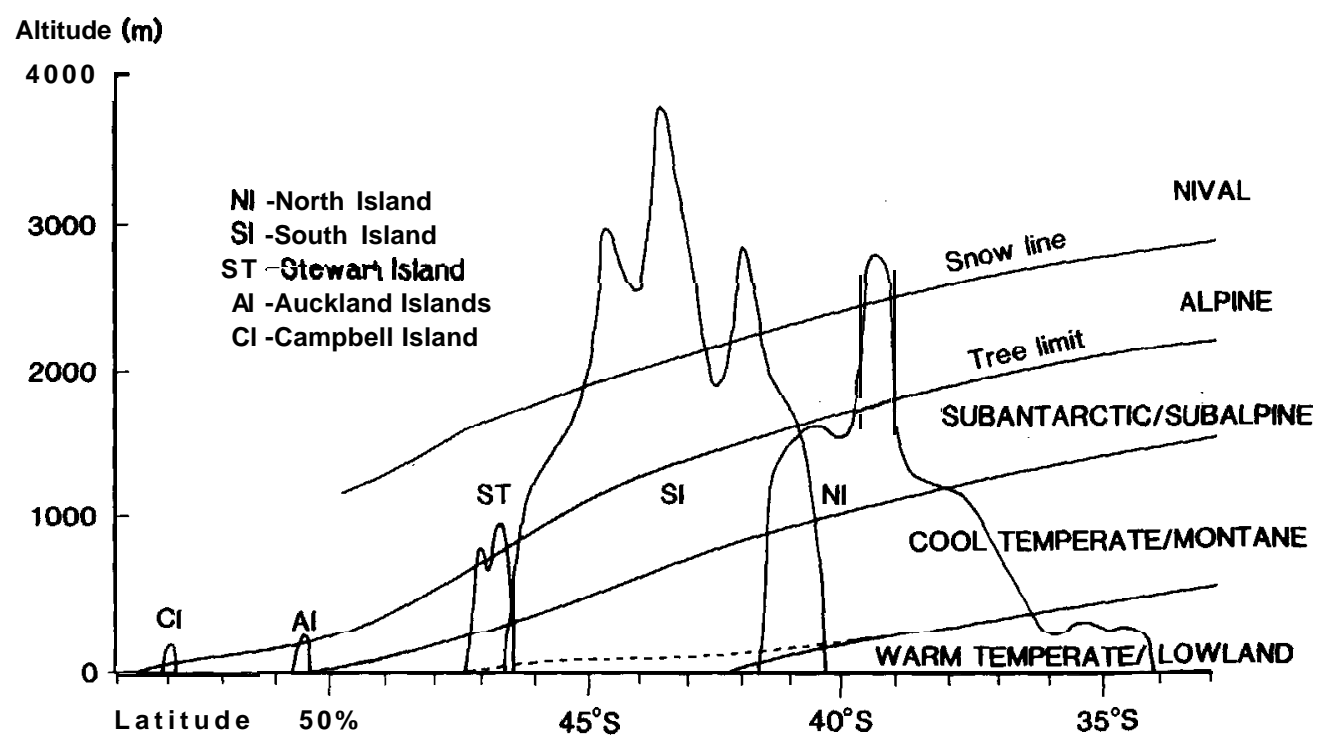

Figure 2 Bioclimatc zones in New Zealand in relation to latitude and altitude, derived from Meurk (1984) Irregularities in zonal patterns are caused by oceanic influences. 
What is important is to realise just how unrepresentative our natural estate is (Figure 3). We have a habit of self-righteously pointing to our national parks as our bit for conservation, but this serves only to reveal our alienation from the whole environment that nurtures us. Conservation begins at home it is not something to be banished to the retreating frontiers.

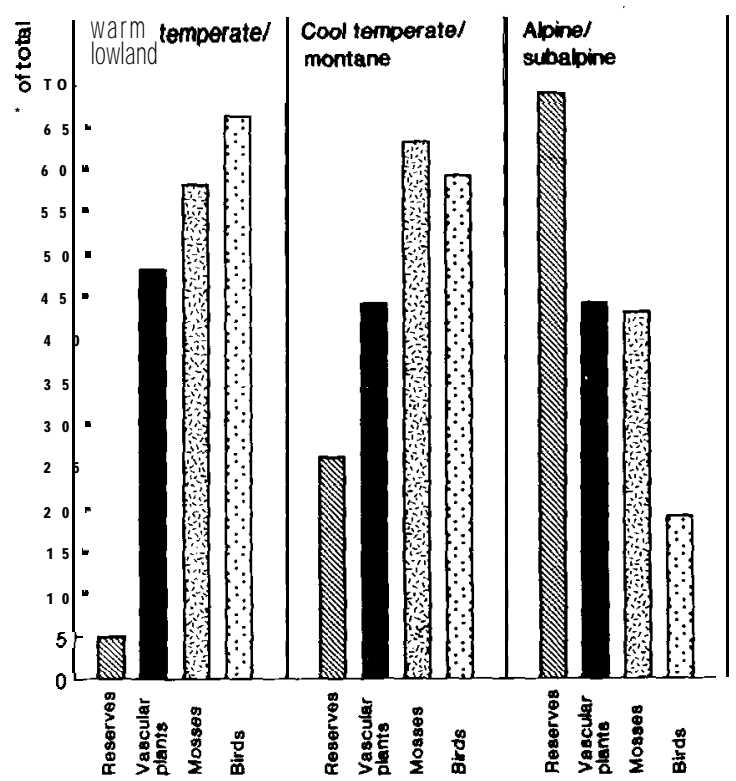

Figure 3 Relative proportions of nature reserves (area). indigenous vascular plants. mosses. and terrestrial birds (species numbers), in three bingeographic zones of New Zealand. Totals used arc c. 4591931 ha (Timmins \& King 1984). 2362 vascular plant taxa (A.P. Druce pers. comm 1989). 506 moss taxa (A.J. Fife pers. Comm. 1989), and 32 bird species (C.F.J. O'Donnell pers. comm. I 989).

Perhaps the greatest threats are fashion and trends which create sterile uniformity - a habit of 'tidiness' that brooks no scrub-tilled gully, no blot of uncontrolled seepage, no native remnants lining our road verges, nor shrubs, tussocks and trees dotted through our pastures. In the quelling of nature's signals, districts and regions become indistinguishable from one another, and what is worse we become indistinguishable from other temperate parts of the world. After all most countries have mountains, most countries have warm sun, beaches, western fads, and forests (indeed most countries including Japan, Austria and Scandinavia have a higher proportion of forests than New Zealand). What we have is relatively clean air and water, a unique biological history (more than $75 \%$ of our plants and animals are found nowhere else), a Polynesian culture indigenous to this land, and an emerging, distinctively New Zealand, bicultural nationhood. Nowhere else did the Gondwana heritage survive into the modem era largely undiluted by Eurasian or northern influences. And then there are the regional variations - the kauri and pohutukawa of the north, the red tussock and beech forests of the volcanic plateau and Southland, the cabbage trees, kanuka, matagouri and short grasslands of the east, and the tall podocarp forests of the west.

Our landscapes are richly embroidered with signs of the genesis, evolution and succession of layers of history. These are our strengths; we must foster and build on them. Tourists will tire of coming to see (pale) replicas of their own intemationalised cultures and landscapes. They want novel experiences.

\section{VALUES AND VALUE-ADDED!}

How do we assess the desirability of all these changes - the restlessness of the land and its people? Some changes give very clear economic messages, such as the effects of deforestation on the Cyclone Bola country and in the Wairarapa. Is burning scrub the answer; perhaps the nitrogenfixing matagouri (tumatakuru) and kowhai could be allies in the fight against drought'! Continual burning, clearing, overgrazing and draining of peatlands all oxidise or 'mine' organic matter and contribute to the potentially ruinous greenhouse effect. Other perspectives, such as the aesthetic desirability of maintaining native species in the landscape, can be demonstrated, but are ultimately more value-based. But this is the subject of our debate - the growing-pains of a transition to nationhood, asserting our national and local character. Why are we different; what is distinctive about us; how do we develop a culture (or mix of cultures) that is uniquely us, which is well-rooted to our history and our land? One of the obvious components is the heritage of Gondwana, its adaptations to the journey of an isolated oceanic island, and to the more recent human passengers who formed or are forming a reciprocal relationship with the environment. To flourish, culture must embrace nature, not keep it at arm's length or in a glass case. We must imbibe the linkages to land, history and culture into our national psyche.

\section{THE WAY AHEAD - A LANDSCAPE THAT IS US}

Humans have now the unique and frightening capacity to modify the world for good or evil. Land people, more than any, are at the cutting edge of landscape change. The future regional councils offer new opportunities for a rural and urban partnership in shaping tomorrow's landscapes - one which is sensitivities to and grows spontaneously from the soil, but inevitably one which reflects our aspirations as a nation. We have taken so much, but it is now time to put something back. There is really little 
time to lose. We all have immense responsibilities to protect what little is left down on the farm and, where necessary, restore those natural areas that are so central to our identity. An emasculated Department of Conservation does not have the resources to do the whole job. Only your individual actions in conjunction with covenanting agencies such as the QEII Trust and DOC and Protected Maori land agreements can avert a biologically and aesthetically desolate future for our children.

The concept of Protected Natural Areas has not been fully developed. It has dealt largely with the remote, sparsely populated areas where the conflicts are least. The real issues are in the lowlands, on the farms, in and around the cities, where we all live. This is where we desperately need the reminders of our heritage, where we generate our knowledge, sensitivities and understanding of how our future is tied to our history and the productivity, vitality, and diversity of the land. We must feel at ease with our environment, not that we have to bulldoze, slash, rip, drain, bum, spray and concrete it into submission. The reserves and parks are fine, but there must be an organic link between the reserves, which forms a fabric to the landscape, which allows genetic flow to continue, corridors for wildlife, and a comfortable feeling of belonging.
In practical terms this means retaining the scrubby gullies and aiding their regeneration; retaining scattered native trees and planting their offspring to replace those that die; keeping stock out of the bush remnants and swamps. It means recognising their values to the future and what they embody in terms of the amazing origins of Aotearoa.

The real challenges that lie ahead are the global environmental issues. But charity begins at home. We each have to be secure in our own everyday relationship with the land and nature, and then the larger picture will fall into place. Think globally, act locally!

\section{REFERENCES}

Holdaway. R.N. 1989. New Zealand's pre-human avifauna and its vulnerabilitv. NZ Journal of Ecologv 12 (supplement): 11.12

Meurk. C.D. 1984. Bioclimatic zones for the Antipodes and beyond? NZ Journal of Ecology 7: 175-1 81.

Timmins, S.: King, K. (Eds.) 1984. Register of Protected $N$ atural Areas in New Zealand, Department of Lands and Survey, Wellington. 